\title{
The role of climate factors in geographic variation in body mass and wing length in a passerine bird
}

\author{
Yanfeng Sun ${ }^{1,2}$, Mo Li ${ }^{1}$, Gang Song ${ }^{3}$, Fumin Lei ${ }^{3}$, Dongming Li $i^{*}$ (D) and Yuefeng Wu${ }^{1 *}$
}

\begin{abstract}
Background: Geographic variation in body size is assumed to reflect adaptation to local environmental conditions. Although Bergmann's rule is usually sufficient to explain such variation in homeotherms, some exceptions have been documented. The relationship between altitude, latitude and body size, has been well documented for some vertebrate taxa during the past decades. However, relatively little information is available on the effects of climate variables on body size in birds.
\end{abstract}

Methods: We collected the data of 267 adult Eurasian Tree Sparrow (Passer montanus) specimens sampled at 48 localities in China's mainland, and further investigated the relationships between two response variables, body mass and wing length, as well as a suit of explanatory variables, i.e. altitude, latitude, mean annual temperature (MAT), annual precipitation (PRC), annual sunshine hours (SUN), average annual wind speed (WS), air pressure (AP) and relative humidity $(\mathrm{RH})$.

Results: Our study showed that (1) although the sexes did not differ significantly in body mass, males had longer wings than females; (2) body mass and wing length were positively correlated with altitude but not with latitude; (3) body mass and wing length were negatively correlated with AP and RH, but not significantly correlated with WS. Body mass was positively correlated with SUN and inversely correlated with MAT. Wing length was not correlated with MAT in either sex, but was positively correlated with SUN and negatively correlated with PRC in male sparrows; (4) variation in body mass could be best explained by AP and SUN, whereas variation in wing length could be explained by RH and AP in both sexes. In addition, variation in male sparrows can be explained by SUN, WS and PRC but not in females.

Conclusions: Two different proxies of body size, body mass and wing length, correlated with same geographic factors and different climate factors. These differences may reflect selection for heat conservation in the case of body mass, and for efficient flight in the case of wing length.

Keywords: Body mass, Wing length, Altitude, Latitude, Climate factor, Eurasian Tree Sparrow

\section{Background}

Body size is arguably the most important trait affecting the physiology and ecology of animals (Schmidt-Nielsen 1984; Lomolino and Perault 2007; Kingsolver and Huey 2008). Intraspecific, geographic variation in body size is assumed to reflect adaptation to local environmental

\footnotetext{
*Correspondence: lidongming@hebtu.edu.cn; wuyuefeng@hebtu.edu.cn 1 Key Laboratory of Animal Physiology, Biochemistry and Molecular Biology of Hebei Province, College of Life Sciences, Hebei Normal University, Shijiazhuang 050024, China

Full list of author information is available at the end of the article
}

conditions (Mayr 1956; Millien et al. 2006; Yom-Tov and Geffen 2011). Bergmann's rule, which postulates that individuals from cooler regions tend to be larger than congeners from warmer regions (McNab 1971), is commonly invoked to explain such variation in both homeotherms (McNab 1971; Blackburn and Ruggiero 2001; Ashton 2002a; Lin et al. 2008; Martinez et al. 2013) and ectotherms (Ashton 2002b; Jin et al. 2006; PincheiraDonoso et al. 2008; Jaffe et al. 2016). This rule has been corroborated by data on numerous bird and mammal species in the past few decades; however, a few notable 
exceptions have been documented (reviewed by Ashton 2002a and Meiri and Dayan 2003).

Both increasing altitude and latitude are generally negatively correlated with temperature (Blackburn et al. 1999; Potapov 2004; Keller et al. 2013). Previous studies have demonstrated a positive relationship between body size and latitude in both birds and mammals (Ashton 2002a; Meiri and Dayan 2003; Gardner et al. 2009; Olson et al. 2009). However, limited information is available on altitudinal variation in body size (Hamilton 1961; Blackburn and Ruggiero 2001; Chown and Klok 2003; Wilson et al. 2010; Gutiérrez-Pinto et al. 2014). Although latitudinal and altitudinal gradients show similar temperature trends (Ashton and Feldman 2003), some climate factors, such as solar radiation, air pressure (AP) (or oxygen concentration), are more strongly associated with variation in altitude than latitude (Liao et al. 2006; Körner 2007, also see Additional file 1: Table S1). The effects of such climate factors on body size could be as, or more, important than the effects of temperature (Liao et al. 2006; Zhao et al. 2013).

McNab (2010) argued that vertebrates become larger or smaller geographically depending on the abundance, availability and size of resources, and termed this pattern as the "resource rule". Food availability (i.e. quantity and quality of nutrition, often use net primary productivity as proxy), especially during the growth period, is a crucial predictor determining the final body size, which is impacted directly or indirectly by some abiotic factors such as solar radiation, precipitation, humidity and temperature and others (Rosenzweig 1968; Yom-Tov and Geffen 2011).

It was well known that animals at high altitude must adapt to the stress of lower AP (or oxygen concentration) relative to sea level and still sustain aerobic metabolic processes. Although animals inhabiting higher altitudes generally have higher energy demands for cold surroundings (Snyder 1981; Chappell et al. 1988), limited oxygen availability might decrease digestive efficiency and thus affect negatively their body size. This mechanism has been demonstrated in geographic size variation in lizards and mammals (Jin et al. 2006, 2007; Liao et al. 2006). However, there is little available information on the effect of AP on body size in birds.

Wind speed (WS) has two aspect functions on the body size of an animal. In addition to imposing a thermoregulatory constraint on organisms along with ambient temperature (wind chill effect, Goldstein 1983), strong wind also cause animals, especially flyers, to consume more energy during flight (Bowlin and Wikelski 2008). Therefore, many flying vertebrates and invertebrates modify their wing length or shape to avoid the negative impacts brought by high WS. For example, the elytra and wings of grasshoppers in the Tibetan Plateau have degenerated or even disappeared (Yin 1984). Wing length of European Storm Petrels (Hydrobates pelagicus) tends to increase at high latitudes perhaps in response to local ambient temperature and WS (Jakubas et al. 2014).

Species with large geographic ranges are more likely to exhibit geographic clines in body size (Meiri et al. 2007) because they encounter, and must adapt to, a diverse gradient of environmental conditions throughout their range. This is especially true of sedentary birds (Meiri and Dayan 2003). From this perspective, the Eurasian Tree Sparrow (P. montanus), a species resident within a vast geographic range that includes both low and high altitude areas of the Eurasian continent (Fu et al. 1998; Summers-Smith 2009), is an ideal candidate for the study of geographic variation in body size. In this study, we present data on altitudinal and latitudinal variation in body mass and wing length in Chinese populations of the Eurasian Tree Sparrow and use these data to determine whether Bergmann's rule applies to this species. In addition, we analyze the relationships between body mass, wing length and selected climate factors, including mean annual temperature (MAT), annual precipitation (PRC), annual sunshine hours (SUN), annual average WS, AP and relative humidity $(\mathrm{RH})$ and determine which of these factors are likely to have the greatest effect on body mass and wing length in the Eurasian Tree Sparrow.

\section{Methods}

\section{Data collection}

This study was based on Eurasian Tree Sparrow specimens housed at the National Zoological Museum of China, Beijing. Body mass, wing length, sex, acquisition time and sites [latitude $\left({ }^{\circ}\right)$, longitude $\left(^{\circ}\right)$ and altitude $(\mathrm{m})$ ] of each individual were extracted from the records of the original collection. In order to ensure the accuracy and reliability of the data, individual birds with worn feathers, or those that were collected during the pre-basic molt stage and breeding stage were excluded from our sample. In the end, we had obtained the body mass and wing length measurements of 267 adult specimens (153 males and 114 females) sampled between 1960 and 1980 at 48 localities in China's mainland at altitudes ranging from -130 to $4370 \mathrm{~m}$ above the sea level and at latitudes ranging from $26^{\circ} 04^{\prime} \mathrm{N}$ to $52^{\circ} 04^{\prime} \mathrm{N}$ (Additional file 1: Table S2).

Because body mass and wing length would be expected to be related to climate conditions in the year in which specimens were collected (Yom-Tov et al. 2006), we obtained climate data for the sampling sites in the years in which specimens were collected from the China Meteorological Data Sharing Service System (http:// data.cma.gov.cn/site/index.html). These climate data included MAT, PRC, SUN, WS, AP and RH (Additional file 1: Table S2). Of these, MAT, PRC, SUN and RH 
were significantly correlated with altitude and latitude, whereas AP was only correlated with altitude and WS only with latitude (Additional file 1: Table S1).

\section{Statistical analysis}

We conducted one-sample Shapiro-Wilk test and Levene's test to determine whether data conform to normal distribution and homogeneity of variances. Since body mass and wing length may be affected by gender (Fairnbairn et al. 2007), we ran linear mixed-effect models (LME) fitted with the restricted maximum likelihood (REML) method using the lme function of nlme package in Program R v. 3.2.2 (Pinheiro et al. 2015) to examine the fixed effects of sex (as dummy variable) on body mass and wing length, while accounting for collection site and individual identity as random effects. We further examined the relationship between body mass and wing length for each gender. LME fitted with the REML method was also used to examine the fixed effects of each geographic/climatic factor on body mass/wing length while accounting for collection site and individual identity as random effects. These statistical analyses were performed using Program R v. 3.2.2. The data are presented as mean $\pm \mathrm{SE}$.

We ran a generalized linear model (GLM) using the $\mathrm{glm}$ function in Program R v. 3.2.2 to model the relationship between body mass or wing length and AP, PRC, SUN, WS, RH and MAT. Because male sparrows had longer wings than females (see "Results" sect.), we analyzed the relationship between wing length and other factors for males and females separately. We used Akaike's Information Criterion (AIC) to select the best model(s). Multiparameter models were discarded if a nested model (collinearity among the climate factors), containing a subset of the same parameters, had a better AIC score (Arnold 2010). All possible models within 95\% cumulative AIC weight for body mass and wing length were selected and averaged to identify the most important variables using the importance score in the Program $\mathrm{R} v$. 3.2.2 MuMIn package (Kamil 2013).

\section{Results}

Although there was no significant difference in body mass between the sexes $(t=-0.444, p=0.675)$, male sparrows had longer wings than females $(t=-4.473$, $p<0.001$; Fig. 1a). Therefore, data on body mass were pooled for analysis whereas wing length data were analyzed separately for each sex (Table 1). Body mass was positively correlated with wing length in each sex (male: $t=3.856, p<0.001$; female: $t=4.459, p<0.001$; Fig. 1b). Body mass and wing length in both sexes were positively correlated with altitude, but were not significantly correlated with latitude (Table 1, Fig. 2a, b).
Among the six climate factors examined, body mass and wing length were negatively correlated with AP, and $\mathrm{RH}$, but not significantly with WS in either sex (Table 1 ; Figs. 3a, b, 4a, b). Body mass was negatively correlated with MAT and positively correlated with SUN (Table 1; Fig. 3c, d). Wing length was not significantly correlated with MAT in either sex, nor with PRC and SUN in females, but was positively correlated with SUN and negatively correlated with PRC in males (Table 1; Fig. 4c, d).

AP, SUN and PRC were the best predictors of body mass, explaining $50 \%$ of all variation in this variable (Additional file 1: Table S3). Of these factors, AP and SUN were the most important (Table 2). In males, AP, PRC, RH, SUN and WS were the best predictors of wing length, explaining $50 \%$ of all variation in this variable (Additional file 1: Table S3). The relative importance coefficients of these five factors were all greater than 0.6 (Table 2). However, in females, RH, AP and PRC were the best predictors explaining $32 \%$ of all variation in this variable (Additional file 1: Table S3). Of these, $\mathrm{RH}$ and AP were the most important climate factors (Table 2).

\section{Discussion \\ Geographic and climatic variation in body mass and wing length}

Consistent with Bergmann's rule, we found that Eurasian Tree Sparrows were heavier at higher altitudes, with a negative correlation between body mass and MAT. This trend has also been reported in a number of sedentary and migratory bird species, such as House Sparrows (Passer domesticus; Johnston and Selander 1973), Crested Duck (Lophonetta specularioides; Bulgarella et al. 2007), Torrent Duck (Merganetta armata; Gutiérrez-Pinto et al. 2014) and some Andean passerine birds (Blackburn and Ruggiero 2001), but not in the Rufous-necked Snowfinch (Montifringilla ruficollis; Lu et al. 2009). From a thermoregulatory viewpoint, increased body mass could be an adaptation to colder temperatures (Gardner et al. 2009; Teplitsky and Millien 2014); the reduced surface area to volume ratio of larger-bodied individuals means that they lose proportionately less heat than smaller-bodied birds (Mayr 1956, 1963; Blackburn et al. 1999).

In the present study, we found a positive relationship between wing length and body mass in both sexes, while both surrogates of body size were positively correlated with altitude. In birds, wing length is commonly considered an index of lean body mass (Nolan and Ketterson 1983), so the increased body mass at higher altitudes could be mainly the result of an increase in wing size and flight muscle (Sun et al. 2016), or an increase in the size of metabolic and respiratory organs, i.e. the heart and lungs (Hartman 1955; Carey and Morton 1976; Sun et al. 2016). 

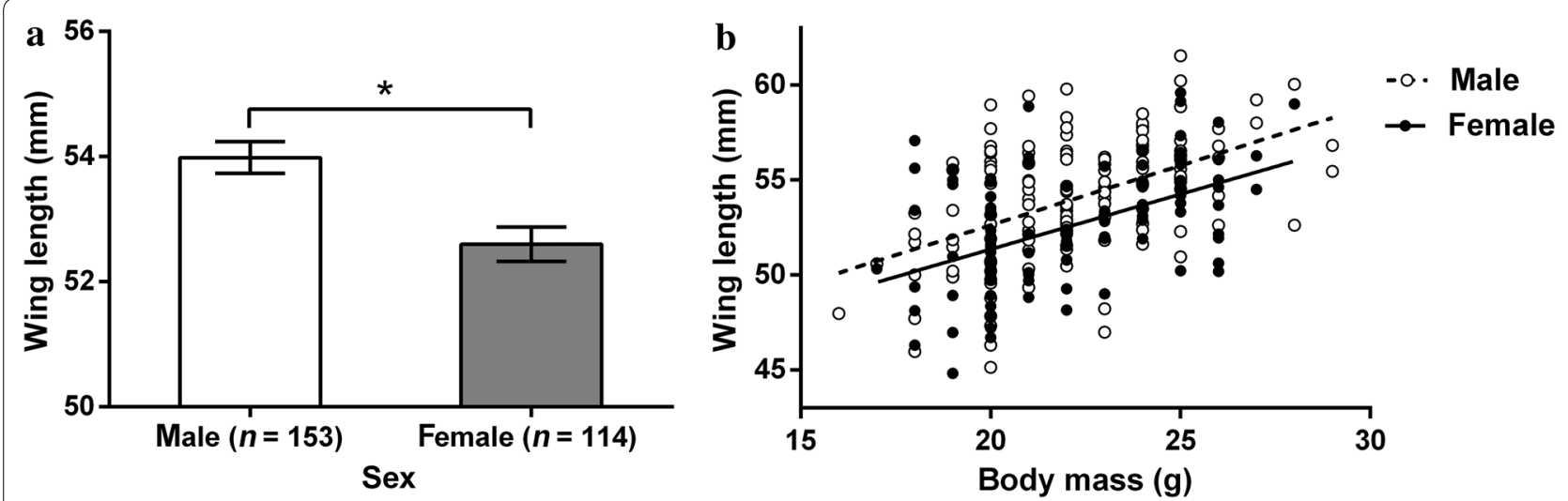

Fig. 1 Sexual size dimorphism in wing length and body mass in Passer montanus. a Mean male and female wing length (mean $\pm S E$, the asterisk represents a statistically significant difference between the sexes). b Relationship between wing length and body mass (males: $\mathrm{df}=151, t=3.856$, $p<0.001$, open circles and dashed lines; females: $\mathrm{df}=112, t=4.459, p<0.001$, black dots and solid lines)

Table 1 Correlations between body mass or wing length of $P$. montanus and geographic and climate factors

\begin{tabular}{|c|c|c|c|c|c|c|c|c|c|}
\hline Variable & $\begin{array}{l}\text { Statistical } \\
\text { parameter }\end{array}$ & Altitude & Latitude & MAT & AP & PRC & SUN & $\mathrm{RH}$ & WS \\
\hline \multicolumn{10}{|l|}{ Body mass } \\
\hline & $d f$ & 218 & 218 & 46 & 46 & 46 & 46 & 46 & 46 \\
\hline & Estimate & 0.001 & -0.026 & -0.123 & -0.010 & -0.001 & 0.002 & -0.070 & 0.422 \\
\hline & $t$ & 4.125 & -0.518 & -2.243 & -4.088 & -1.542 & 2.751 & -2.768 & 1.138 \\
\hline & $p$ & $<0.001$ & 0.605 & 0.026 & $<0.001$ & 0.130 & 0.006 & 0.006 & 0.261 \\
\hline \multicolumn{10}{|c|}{ Wing length } \\
\hline \multirow[t]{4}{*}{ Male } & $d f$ & 113 & 113 & 37 & 37 & 37 & 37 & 37 & 37 \\
\hline & Estimate & 0.001 & -0.052 & -0.004 & -0.009 & -0.003 & 0.002 & -0.129 & 0.167 \\
\hline & $t$ & 2.972 & -0.868 & -0.060 & -2.643 & -2.884 & 4.065 & -5.407 & 0.341 \\
\hline & $p$ & 0.004 & 0.388 & 0.952 & 0.012 & 0.007 & $<0.001$ & $<0.001$ & 0.735 \\
\hline \multirow[t]{4}{*}{ Female } & $d f$ & 77 & 77 & 34 & 34 & 34 & 34 & 34 & 34 \\
\hline & Estimate & 0.001 & -0.123 & 0.052 & -0.009 & -0.001 & 0.000 & -0.067 & -0.557 \\
\hline & $t$ & 2.811 & -2.014 & 0.682 & -2.807 & -0.559 & 0.325 & -2.027 & -1.031 \\
\hline & $p$ & 0.006 & 0.050 & 0.497 & 0.008 & 0.580 & 0.746 & 0.046 & 0.310 \\
\hline
\end{tabular}

Estimate model coefficients, $d f$ degree of freedom, MAT mean annual temperature, $P R C$ annual precipitation, SUN annual sunshine hours, WS annual average wind speed, $A P$ air pressure, $R H$ relative humidity. Data on the body mass of each sex were pooled but wing length data were analyzed separately for each sex

From the point of view of ambient temperature, animals should exhibit a uniform body size cline along with latitude and altitude (Ashton and Feldman 2003). However, the increasing body size of Eurasian Tree Sparrow was only accompanied with rising altitude, but not with latitude. The different trends in body mass and wing length with increasing altitude or latitude suggest that climate factors other than temperature could have an important effect on body size. For example, variation in AP or oxygen concentration is directly affected by altitude, but rarely by latitude. We found an inverse correlation between AP and both body mass and wing length. As mentioned in the introduction, there is a dilemma that maximum metabolic rates of birds will decrease when they are under low oxygen concentration and increase when they are stressed by low environmental temperatures. The lower wing loadings of longer wings can offset the increased energy requirements incurred by the lower air density at higher altitudes (Swaddle and Lockwood 2003; Altshuler and Dudley 2006). Birds living at higher altitudes typically have a larger heart and lungs in order to provide adequate oxygen to meet metabolic requirements, especially the requirements of flight (Hartman 1955; Carey and Morton 1976; Monge and Leon-Velarde 1991; Scott 2011). The hearts and lungs of Eurasian Tree Sparrows collected at higher altitudes were heavier than those of conspecifics collected at lower altitudes (Sun et al. 2016). This suggests that the positive correlations 

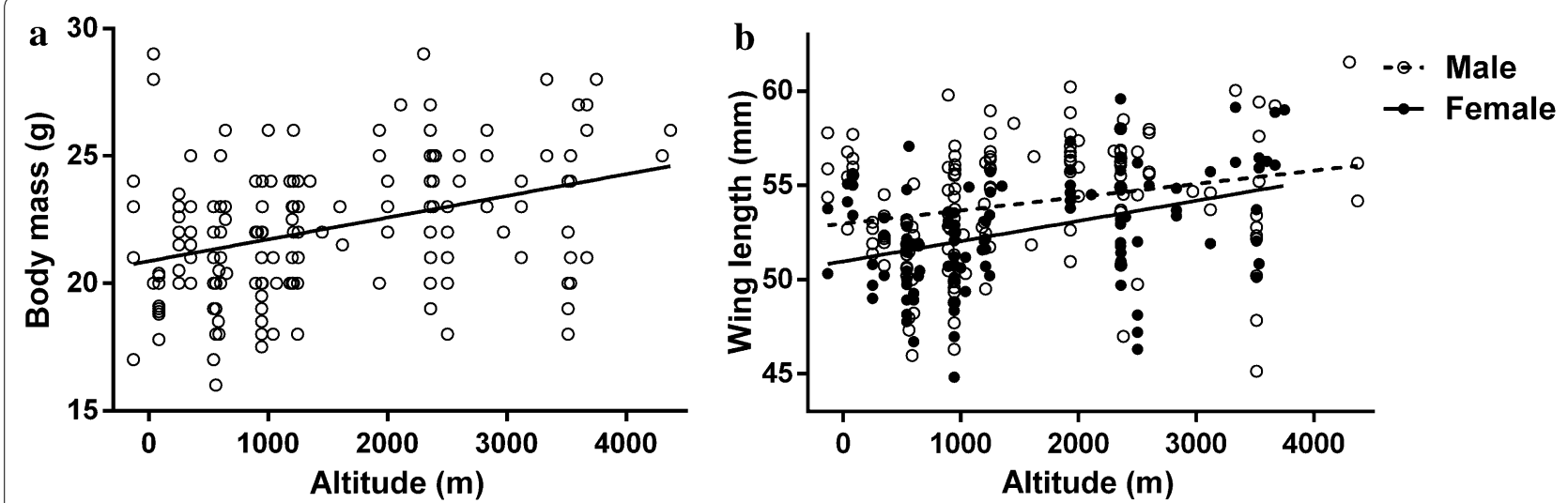

Fig. 2 Correlations between body mass or wing length of $P$. montanus and altitude. a Body mass vs altitude ( $\mathrm{df}=218, t=4.125, p<0.001)$, $\mathbf{b}$ wing length versus altitude (male: $\mathrm{df}=113, t=2.972, p=0.004$, open circles and dashed lines; female: $\mathrm{df}=77, t=2.811, p=0.006$, black dots and solid lines)
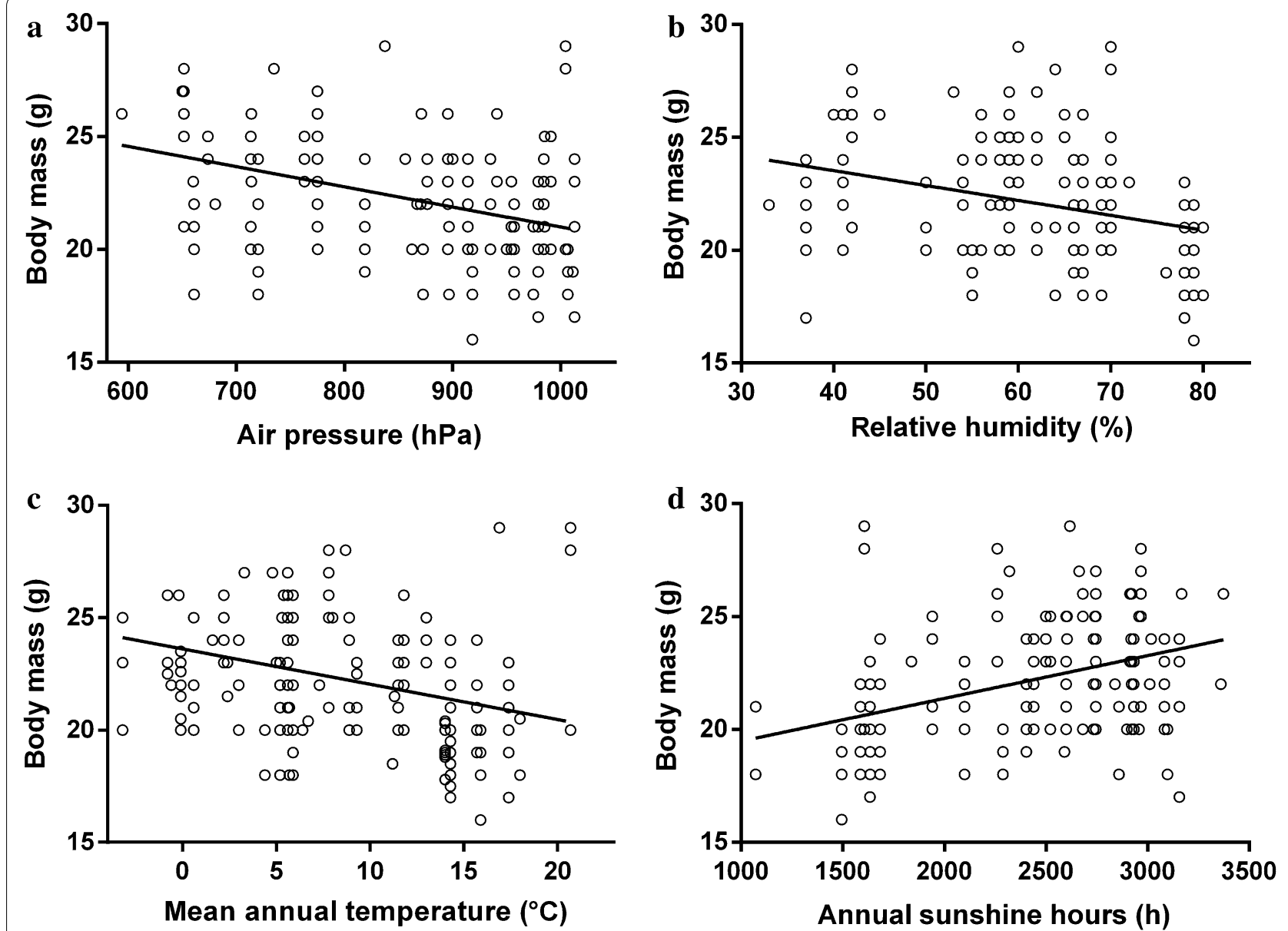

Fig. 3 Correlations between body mass of $P$. montanus and climate factors. a Air pressure ( $\mathrm{df}=46, t=-4.088, p<0.001)$, b relative humidity $(\mathrm{df}=46, t=-2.768, p=0.006)$, c mean annual temperature $(\mathrm{df}=46, t=-2.243, p=0.026)$ and $\mathbf{d}$ annual sunshine hours $(\mathrm{df}=46, t=2.751$, $p=0.006)$, at collection sites 

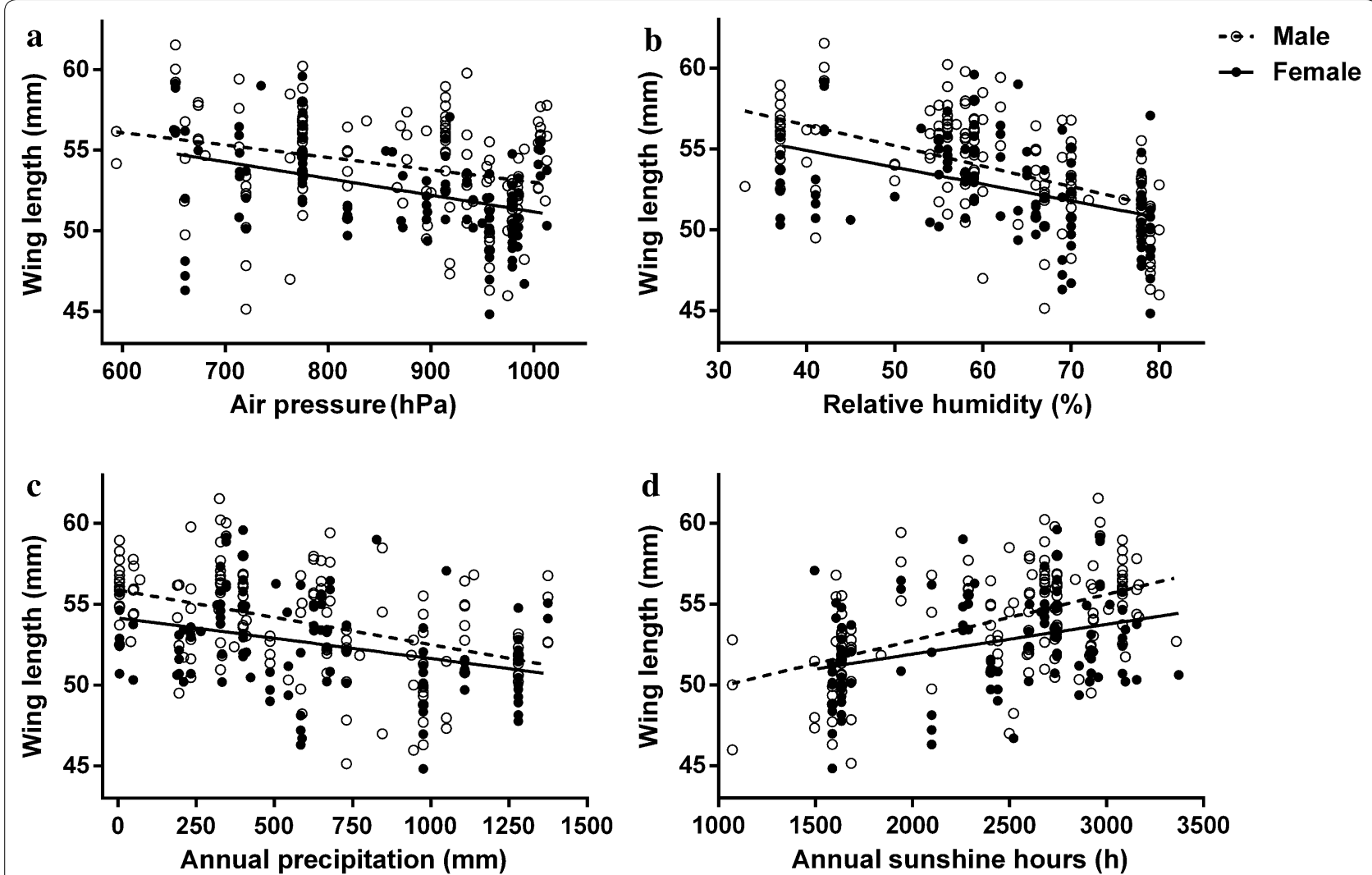

Fig. 4 Correlations between wing length of $P$. montanus and climate factors. a Air pressure (male: $\mathrm{df}=37, t=-2.643, p=0.012 ; \mathrm{female}: \mathrm{df}=34$, $t=-2.087, p=0.008$ ), b relative humidity (male: $\mathrm{df}=37, t=-5.407, p<0.001$; female: $\mathrm{df}=34, t=-2.027, p=0.046$ ), c annual precipitation (males: $\mathrm{df}=37, t=-2.884, p=0.007$; female: $\mathrm{df}=34, t=-0.559, p=0.580$ ), and $\mathbf{d}$ annual sunshine hours (males: $\mathrm{df}=37, t=4.605, p<0.001$; female: $\mathrm{df}=34, t=0.325, p=0.746)$, at collection sites. Data on males are shown as open circles and dashed lines and those on females as black dots and solid lines

between body mass or wing length and altitude may not only reflect adaptations to reduce energy consumption, but also to ensure an adequate oxygen supply.

We found that SUN was positively correlated with both wing length (only for males) and body mass in the Eurasian Tree Sparrow. A sufficient amount of sunshine is conducive to improving food availability by increasing net primary productivity (Churkina and Running 1998; Yom-Tov and Geffen 2011) and raising plant nutrient levels (Potapov 2004). Increased food availability is generally associated with an increase in body size (Yom-Tov and Nix 1986; Aava 2001; Yom-Tov and Geffen 2006, 2011). The Eurasian Tree Sparrow is a typical omnivorous passerine and mainly feeds on grass seeds, fruits and small insects (Fu et al. 1998). Higher sunshine hours per year would not only provide sparrows with more abundant and more nutritious foods, but also extend their available foraging time, thereby making it easier for the birds to accumulate energy and gain body mass.
Unexpectedly, we found that RH was negatively correlated with wing length and body mass and that PRC was negatively correlated with wing length of male sparrows. A similar trend has been reported in the Crested Lark (Galerida cristata; Guillaumet et al. 2008). One explanation for this may be the necessity to minimize water loss in cold, dry environments (James 1970; Burnett 1983; Lin et al. 2008). Because the rate of water loss mainly depends on the relative surface area of an organism and its metabolic rate (Chew 1955; Chew and Dammann 1961; Lin et al. 2008), it follows that small-bodied individuals are more vulnerable to acute dehydration than large-bodied ones (Hamilton 1958, 1961; James 1970; Olalla-Tárraga et al. 2009; McKechnie and Wolf 2010).

There was no any correlation between WS and body mass. However, WS is one of most important climate factors for explaining wing length in male but not in female Eurasian Tree Sparrows. Previous studies have reported mixed patterns of the effect of WS on body mass, e.g. positive correlation in Gray Jays (Perisoreus 
Table 2 Coefficients of averaged models explaining body mass and wing length (male and female) in relation to climate factors

\begin{tabular}{|c|c|c|c|c|c|c|c|}
\hline Variable & Factor & Estimate & SE & $P$ value & Lower $\mathrm{Cl}$ & Upper Cl & $\begin{array}{l}\text { Relative } \\
\text { importance }\end{array}$ \\
\hline \multicolumn{8}{|l|}{ Body mass } \\
\hline & (Intercept) & 24.181 & 2.493 & $<0.001$ & 19.287 & 29.075 & \\
\hline & AP & -0.008 & 0.001 & $<0.001$ & -0.010 & -0.005 & 1.00 \\
\hline & SUN & 0.002 & 0.001 & 0.001 & 0.001 & 0.003 & 0.96 \\
\hline & PRC & 0.001 & 0.001 & 0.453 & 0.0004 & 0.003 & 0.54 \\
\hline \multicolumn{8}{|c|}{ Wing length } \\
\hline \multirow[t]{7}{*}{ Male } & (Intercept) & 57.864 & 4.750 & $<0.001$ & 48.517 & 67.211 & \\
\hline & SUN & 0.002 & 0.001 & 0.018 & 0.001 & 0.004 & 0.97 \\
\hline & WS & -0.740 & 0.428 & 0.085 & -1.537 & -0.141 & 0.88 \\
\hline & $\mathrm{RH}$ & -0.099 & 0.052 & 0.057 & -0.182 & -0.051 & 0.85 \\
\hline & AP & -0.004 & 0.003 & 0.149 & -0.009 & $<0.001$ & 0.84 \\
\hline & PRC & 0.002 & 0.001 & 0.256 & 0.000 & 0.005 & 0.68 \\
\hline & MAT & 0.022 & 0.054 & 0.688 & 0.054 & 0.229 & 0.15 \\
\hline \multirow[t]{6}{*}{ Female } & (Intercept) & 66.425 & 2.666 & $<0.001$ & 61.158 & 71.693 & \\
\hline & $\mathrm{RH}$ & -0.130 & 0.060 & 0.030 & -0.248 & -0.012 & 1.00 \\
\hline & AP & -0.006 & 0.003 & 0.063 & -0.012 & -0.003 & 0.85 \\
\hline & PRC & 0.001 & 0.002 & 0.502 & -0.001 & 0.007 & 0.47 \\
\hline & WS & -0.376 & 0.529 & 0.479 & -1.798 & 0.118 & 0.45 \\
\hline & MAT & -0.035 & 0.089 & 0.691 & -0.384 & -0.084 & 0.15 \\
\hline
\end{tabular}

Estimate average model coefficients, $S E$ unconditional standard errors, Lower $C l$ and Upper $C l$ the $95 \%$ confidence limits, $A P$ air pressure, $P R C$ annual precipitation, SUN annual sunshine hours, $R H$ relative humidity, WS annual average wind speed, MAT mean annual temperature

More information for top-ranked models are shown in Additional file 1: Table S3

canadensis; Waite 1992), negative correlation in European Storm Petrels (Hydrobates pelagicus; Jakubas et al. 2014), or no correlation in the Dovekie (Alle alle; Wojczulanis-Jakubas et al. 2011). In general, relatively longer wings can increase flight efficiency (Lockwood et al. 1998); many species, especially in migratory or insectivorous birds, are characterized by long wings for gliding and soaring in strong air currents (Landmann and Winding 1995; Lockwood et al. 1998; Nowakowski 2000). Given that little information is available on the effects of WS and flight ability for this sedentary passerine bird, further investigation of such interspecific and gender differences in flight efficiency are needed to clarify the inconsistent results.

Among the six climate factors, only AP and SUN were important with respect to variation in body mass. $\mathrm{RH}$ and AP were the most important with respect to variation in wing length in both male and female sparrows. In addition, SUN, WS and PRC were the most important in males but not in females. Therefore, altitudinal and latitudinal variation in body mass and wing length in the Eurasian Tree Sparrow appears to be affected by a combination of climate factors and sexual selection. Unexpectedly, although there was a significant correlation between body mass and MAT, the latter was not a reliable predictor of body mass in our statistical model. Since we were not able to obtain a satisfactory answer, we deem it necessary to conduct further research on this aspect.

\section{Sexual size dimorphism in body mass and wing length}

The Eurasian Tree Sparrow is generally considered sexually monomorphic. However, although we found no significant difference in body mass between the sexes, males had longer wings than females. These results are consistent with those obtained for other populations or other subspecies of the Eurasian Tree Sparrow (St. Louis and Barlow 1991; Mónus et al. 2011; Sun et al. 2016). Although sexual displays in birds require much energy (Gil and Gahr 2002; Ward and Slater 2005), male Eurasian Tree Sparrows can behave in the same intensity during autumnal sexual recrudescence as they commonly do at prebreeding (García-Navas et al. 2008; Pinowski et al. 2009). That is, as in the spring, males sing and display in the fall, compete for territories, attract females, build nests and copulate with females (García-Navas et al. 2008; Pinowski et al. 2009). The longer wings in males are thought to reduce the flight costs incurred in sexual display (Møller 1991; Hedenstrom and Møller 1992). Therefore, sexual size dimorphism in wing length in the Eurasian Tree Sparrow 
may reflect male-specific reproductive behavior and in spite of it, this may also covary with a number of other morphological traits (see Table 1 in Mónus et al. 2011). Furthermore, female birds are more susceptible to predators because they incubate or brood the nest, although the short wings of some female passerines may enhance their maneuverability and help them escape predation (Swaddle and Lockwood 2003; Bomberger and Brown 2011).

\section{Conclusions}

Geographic variation in body mass and wing length in the Eurasian Tree Sparrow is generally consistent with Bergmann's rule. Body mass and wing length is positively correlated with altitude, but not with latitude, suggesting that the body size of sparrows is more affected by other climate factors than by MAT. Most variation in body mass can be explained by AP and SUN, whereas significant variation in wing length can be best explained by $\mathrm{RH}$ and AP in both males and females. In addition, variation in male sparrows can be explained by SUN, WS and PRC but not in females. Two proxies of body size, i.e. body mass and wing length, displayed different strengths and polarities of correlation with the same geographic and climate factors. These differences may reflect competing selection pressures for heat conservation, flight efficiency and sexual selection.

\section{Additional file}

Additional file 1: Table S1. Partial correlations between the altitude and latitude of Eurasian Tree Sparrow (Passermontanus) collection sites and selected climatic factors. Table S2. Sampling information of Eurasian Tree Sparrows and climate data of their collection sites. Table S3. Top-ranked cumulative link models of the relationship between body mass or wing length of the Eurasian Tree Sparrow and potential explanatory factors.

\section{Authors' contributions}

YFS, DML and YFW conceived the research project, ML and GS collected the data, YFS analyzed the data and YFS and DML led the writing with help from FML. All authors have read and approved the manuscript.

\section{Author details \\ ${ }^{1}$ Key Laboratory of Animal Physiology, Biochemistry and Molecular Biol- ogy of Hebei Province, College of Life Sciences, Hebei Normal University, Shijiazhuang 050024, China. ${ }^{2}$ Ocean College, Hebei Agricultural University, Qinhuangdao 066003, China. ${ }^{3}$ Key Laboratory of Zoological Systematics and Evolution, Institute of Zoology, Chinese Academy of Sciences, Bei- jing 100101, China.}

\section{Acknowledgements}

We are grateful to the curators of the National Zoological Museum of China for providing locality and other information on specimens. This work was supported by grants from the National Natural Science Foundation of China (NSFC, 31330073, 31672292) and the Natural Science Foundation of the Department of Education, Hebei Province (YQ2014024).

\section{Competing interests}

The authors declare that they have no competing interests.

Received: 27 September 2016 Accepted: 19 December 2016 Published online: 25 January 2017

\section{References}

Aava B. Primary productivity can affect mammalian body size frequency distributions. Oikos. 2001:93:205-12.

Altshuler DL, Dudley R. The physiology and biomechanics of avian flight at high altitude. Integr Comp Biol. 2006;46:62-71.

Arnold TW. Uninformative parameters and model selection using Akaike's information criterion. J Wildl Manage. 2010;74:1175-8.

Ashton KG, Feldman CR. Bergmann's rule in nonavian reptiles: turtles follow it, lizards and snakes reverse it. Evolution. 2003;57:1151-63.

Ashton KG. Do amphibians follow Bergmann's rule? Can J Zool. 2002a;80:708-16

Ashton KG. Patterns of within-species body size variation of birds: strong evidence for Bergmann's rule. Glob Ecol Biogeogr. 2002b;11:505-23.

Blackburn TM, Gaston KJ, Loder N. Geographic gradients in body size: a clarification of Bergmann's rule. Divers Distrib. 1999;5:165-74.

Blackburn TM, Ruggiero A. Latitude, elevation and body mass variation in Andean passerine birds. Glob Ecol Biogeogr. 2001;10:245-59.

Bomberger BM, Brown CR. Intense natural selection on morphology of cliff swallows (Petrochelidon pyrrhonota) a decade later: did the population move between adaptive peaks? Auk. 2011;128:69-77.

Bowlin MS, Wikelski M. Pointed wings, low wingloading and calm air reduce migratory flight costs in songbirds. PLOS ONE. 2008;3:e2154.

Bulgarella M, Wilson RE, Kopuchian C, Valqui TH, McCracken KG. Elevational variation in body size of crested ducks (Lophonetta specularioides) from the central high Andes, Mendoza, and Patagonia. Ornitol Neotropical. 2007; 18:587-602.

Burnett CD. Geographic and climatic correlates of morphological variation in Eptesicus fuscus. J Mamm. 1983;64:437-44.

Carey C, Morton ML. Aspects of circulatory physiology of montane and lowland birds. Comp Biochem Phys A. 1976;54:61-74.

Chappell MA, Hayes JP, Snyder LR. Hemoglobin polymorphisms in deer mice (Peromyscus maniculatus): physiology of beta-globin variants and alphaglobin recombinants. Evolution. 1988;42:681-8.

Chew RM, Dammann AE. Evaporative water loss of small vertebrates, as measured with an infrared analyzer. Science. 1961;133:384-5.

Chew RM. The skin and respiratory water losses of Peromyscus maniculatus sonoriensis. Ecology. 1955;36:463-7.

Chown SL, Klok CJ. Altitudinal body size clines: latitudinal effects associated with changing seasonality. Ecography. 2003;26:445-55.

Churkina G, Running SW. Contrasting climatic controls on the estimated productivity of global terrestrial biomes. Ecosystems. 1998;1:206-15.

Fairnbairn DJ, Blanckenhorn W, Székely T. Sex, size, and gender roles. Oxford: Oxford University Press; 2007.

Fu TS, Song YJ, Gao W. Fauna Sinica: Aves. Passeriformes Ploceidae, Fringillidae. Beijing: Science Press; 1998.

García-Navas V, Arroyo L, José Sanz J. Nestbox use and reproductive parameters of Tree Sparrows Passer montanus: are they affected by the presence of old nests? Acta Ornithol. 2008:43:32-42.

Gardner JL, Heinsohn R, Joseph L. Shifting latitudinal clines in avian body size correlate with global warming in Australian passerines. Proc R Soc Lond B. 2009;276:3845-52.

Gil D, Gahr M. The honesty of bird song: multiple constraints for multiple traits. Trends Ecol Evol. 2002;17:133-41.

Goldstein DL. Effect of wind on avian metabolic rate with particular reference to Gambel's quail. Physiol Zool. 1983;56:485-92.

Guillaumet A, Ferdy JB, Desmarais E, Godelle B, Crochet PA. Testing Bergmann's rule in the presence of potentially confounding factors: a case study with three species of Galerida larks in Morocco. J Biogeogr. 2008;35:579-91.

Gutiérrez-Pinto N, McCracken KG, Alza L, Tubaro P, Kopuchian C, Astie A, Cadena CD. The validity of ecogeographical rules is context-dependent: testing for Bergmann's and Allen's rules by latitude and elevation in a widespread Andean duck. Biol J Linn Soc. 2014;111:850-62.

Hamilton TH. Adaptive variation in the genus vzreo. Wilson Bull. 1958:70:307-46.

Hamilton TH. The adaptive significances of intraspecific trends of variation in wing length and body size among bird species. Evolution. 1961;15:180-95.

Hartman FA. Heart weight in birds. Condor. 1955;57:221-38.

Hedenstrom A, Møller AP. Morphological adaptations to song flight in passerine birds: a comparative study. Proc R Soc Lond B. 1992;247:183-7.

Jaffe AL, Campbell-Staton SC, Losos JB. Geographical variation in morphology and its environmental correlates in a widespread North American 
lizard, Anolis carolinensis (Squamata: Dactyloidae). Biol J Linn Soc. 2016;117:760-74.

Jakubas D, Wojczulanis-Jakubas K, Jensen JK. Body size variation of European Storm Petrels Hydrobates pelagicus in relation to environmental variables. Acta Ornithol. 2014;49:71-82.

James FC. Geographic size variation in birds and its relationship to climate. Ecology. 1970;51:365-90.

Jin YT, Liu NF, Li JL. Elevational variation in body size of Phrynocephalus vlangalii in the North Qinghai-Xizang (Tibetan) Plateau. Belg J Zool. 2007;137:197-202.

Jin YT, Tian RR, Liu NF. Altitudinal variations of morphological characters of Phrynocephalus sand lizards: on the validity of Bergmann's and Allen's rules. Acta Zool Sin. 2006;52:838-45 (in Chinese).

Johnston RF, Selander RK. Evolution in the house sparrow. III. Variation in size and sexual dimorphism in Europe and North and South America. Am Nat. 1973;107:373-90.

Kamil B. MuMIn: multi-model inference. R package version 1.9.0. 2013. http:// CRAN.R-project.org $/$ package $=$ MuMIn.

Keller I, Alexander J, Holderegger R, Edwards P. Widespread phenotypic and genetic divergence along altitudinal gradients in animals. J Evol Biol. 2013;26:2527-43.

Kingsolver JG, Huey RB. Size, temperature, and fitness: three rules. Evol Ecol Res. 2008;10:251-68.

Körner C. The use of 'altitude'in ecological research. Trends Ecol Evol. 2007;22:569-74

Landmann A, Winding N. Guild organisation and morphology of high-altitude granivorous and insectivorous birds: convergent evolution in an extreme environment. Oikos. 1995;73:237-50.

Liao JC, Zhang ZB, Liu NF. Altitudinal variation of skull size in Daurian pika (Ochotona daurica Pallas, 1868). Acta Zool Acad Sci Hung. 2006:52:319-29.

Lin G, Ci H, Zhang T, Su J. Conformity to Bergmann's rule in the plateau pika (Ochotona curzoniae Hodgson, 1857) on the Qinghai-Tibetan plateau. Acta Zool Acad Sci Hung. 2008;54:411-8.

Lockwood R, Swaddle JP, Rayner JMV. Avian wingtip shape reconsidered: wingtip shape indices and morphological adaptations to migration. J Avian Biol. 1998:29:273-92.

Lomolino MV, Perault DR. Body size variation of mammals in a fragmented, temperate rainforest. Conserv Biol. 2007;21:1059-69.

Lu X, Ke D, Zeng X, Yu T. Reproductive ecology of two sympatric Tibetan snowfinch species at the edge of their altitudinal range: response to more stressful environments. J Arid Environ. 2009;73:1103-8.

Martinez PA, Marti DA, Molina WF, Bidau CJ. Bergmann's rule across the Equator: a case study in Cerdocyon thous (Canidae). J Anim Ecol. 2013;82:997-1008.

Mayr E. Animal species and evolution. Cambrige: Harvard University Press; 1963.

Mayr E. Geographical character gradients and climatic adaptation. Evolution. 1956;10:105-8.

McKechnie AE, Wolf BO. Climate change increases the likelihood of catastrophic avian mortality events during extreme heat waves. Biol Lett. 2010;6:253-6.

McNab BK. Geographic and temporal correlations of mammalian size reconsidered: a resource rule. Oecologia. 2010;164:13-23.

McNab BK. On the ecological significance of Bergmann's rule. Ecology. 1971;52:845-54

Meiri S, Dayan T. On the validity of Bergmann's rule. J Biogeogr. 2003:30:331-51

Meiri S, Yom-Tov Y, Geffen E. What determines conformity to Bergmann's rule? Glob Ecol Biogeogr. 2007;16:788-94.

Millien V, Kathleen LS, Olson L, Smith FA, Wilson AB, Yom-Tov Y. Ecotypic variation in the context of global climate change: revisiting the rules. Ecol Lett. 2006;9:853-69.

Møller AP. Influence of wing and tail morphology on the duration of song flight in skylarks. Behav Ecol Sociobiol. 1991;28:309-14.

Monge C, Leon-Velarde F. Physiological adaptation to high altitude: oxygen transport in mammals and birds. Physiol Rev. 1991;71:1135-72.

Mónus F, Szabó K, Lózsa A, Pénzes Z, Barta Z. Intersexual size and plumage differences in tree sparrows (Passer montanus): a morphological study based on molecular sex determination. Acta Zool Acad Sci Hung. 2011;57:269-76.

Nolan V Jr, Ketterson ED. An analysis of body mass, wing length, and visible fat deposits of Dark-eyed Juncos wintering at different latitudes. Wilson Bull. 1983:95:603-20.

Nowakowski JJ. Long-term variability of wing length in a population of the Reed Warbler Acrocephalus scirpaceus. Acta Ornithol. 2000;35:173-82.

Olalla-Tárraga MÁ, Diniz-Filho JAF, Bastos RP, Rodríguez MÁ. Geographic body size gradients in tropical regions: water deficit and anuran body size in the Brazilian Cerrado. Ecography. 2009;32:581-90.

Olson VA, Davies RG, Orme CDL, Thomas GH, Meiri S, Blackburn TM, Gaston KJ, Owens IPF, Bennett PM. Global biogeography and ecology of body size in birds. Ecol Lett. 2009;12:249-59.

Pincheira-Donoso D, Hodgson DJ, Tregenza T. The evolution of body size under environmental gradients in ectotherms: Why should Bergmann's rule apply to lizards? BMC Evol Biol. 2008;8:68.

Pinheiro J, Bates D, DebRoy S, Sarkar D. Team RC. nlme: Linear and nonlinear mixed effects models. R package version 3.1-122. 2015. http://CRAN.Rproject.org/package $=$ nlme.

Pinowski J, Pinowska B, Zduniak P, Tryjanowski P, Jerzak L, Romanowski J. Autumn sexual display in tree sparrows [Passer montanus (L).] as a component of the winter survival strategy. Pol J Ecol. 2009;57:159-69.

Potapov RL. Adaptation of birds to life in high mountains in Eurasia. Acta Zool Sin. 2004;50:970-7.

Rosenzweig ML. The strategy of body size in mammalian carnivores. Am Midl Nat. 1968;80:299-315.

Schmidt-Nielsen K. Scaling: Why is animal size so important?. Cambridge: Cambridge University Press; 1984.

Scott GR. Elevated performance: the unique physiology of birds that fly at high altitudes. J Exp Biol. 2011;214:2455-62.

Snyder LR. Deer mouse hemoglobins: Is there genetic adaptation to high altitude? Bioscience. 1981;31:299-304.

St. Louis VL, Barlow JC. Morphometric analyses of introduced and ancestral populations of the Eurasian tree sparrow. Wilson Bull. 1991;103:1-12.

Summers-Smith D. Eurasian tree sparrow (Passer montanus). In: Del Hoyo J, Elliot A, Christie D, editors. Handbook of the birds of the world. Weavers to New world warblers, vol. 15. Barcelona: Lynx Edicions; 2009.

Sun YF, Ren ZP, Wu YF, Lei FM, Dudley R, Li DM. Flying high: limits to flight performance by sparrows on the Qinghai-Tibet Plateau. J Exp Biol. 2016:219:3642-8

Swaddle JP, Lockwood R. Wingtip shape and flight performance in the European Starling Sturnus vulgaris. Ibis. 2003;145:457-64.

Teplitsky C, Millien V. Climate warming and Bergmann's rule through time: is there any evidence? Evol Appl. 2014;7:156-68.

Waite TA. Winter fattening in gray jays: seasonal, diurnal and climatic correlates. Ornis Scand. 1992;23:499-503.

Ward S, Slater PJ. Raised thermoregulatory costs at exposed song posts increase the energetic cost of singing for willow warblers Phylloscopus trochilus. J Avian Biol. 2005;36:280-6.

Wilson RE, Valqui TH, McCracken KG. Ecogeographic variation in Cinnamon Teal (Anas cyanoptera) along elevational and latitudinal gradients. Ornithol Monogr. 2010;67:141-61.

Wojczulanis-Jakubas K, Jakubas D, Welcker J, Harding AM, Karnovsky NJ, Kidawa D, Steen H, Stempniewicz L, Camphuysen CJ. Body size variation of a high-Arctic seabird: the dovekie (Alle alle). Polar Biol. 2011:34:847-54.

Yin XC. The origin of apterousgrasshoppers from Tibetan Plateau. Acta Biol Plat Sin. 1984;2:57-65.

Yom-Tov Y, Geffen E. Geographic variation in body size: the effects of ambient temperature and precipitation. Oecologia. 2006;148:213-8.

Yom-Tov Y, Geffen E. Recent spatial and temporal changes in body size of terrestrial vertebrates: probable causes and pitfalls. Biol Rev. 2011;86:531-41.

Yom-Tov Y, Nix H. Climatological correlates for body size of five species of Australian mammals. Biol J Linn Soc. 1986;29:245-62.

Yom-Tov Y, Yom-Tov S, Wright J, Thorne CJR, Du Feu R. Recent changes in body weight and wing length among some British passerine birds. Oikos. 2006;112:91-101.

Zhao LM, Wang Y, Liu NF, Liao JC. Effects of change in altitude on the auditory bulla of midday gerbil, Meriones meridianus. Pak J Zool. 2013;45:581-8. 